\title{
INFLUENCE OF MIXED FLOWS ON SHIP HYDRODYNAMICS IN DREDGED CHANNELS
}

\author{
Momchil Terziev \\ University of Strathclyde, Department of Naval \\ Architecture, Ocean and Marine Engineering \\ Glasgow, UK
}

\author{
Tahsin Tezdogan \\ University of Strathclyde, Department of Naval \\ Architecture, Ocean and Marine Engineering \\ Glasgow, UK
}

\author{
Atilla Incecik \\ University of Strathclyde, Faculty of \\ Engineering \\ Glasgow, UK
}

\begin{abstract}
Although there is a significant body of research devoted to the shallow water hydrodynamic aspects of ships, several unexamined topics remain. Among these is that of critical outer flow in a dredged channel and its influence on parameters of interest. While empirical methods can be used with ease to resolve this, they can provide results with reliability sufficient only for an early design stage. On the other hand, more sophisticated potential flow theories are either inapplicable or do not perform well at the critical limit. However, RANS (Reynolds Averaged Navier-Stokes) - based tools can accurately capture all underlying phenomena without relying on limiting assumptions. This paper presents an attempt at comparing some results obtained via a CFD-based RANS solver and the slender body theory for critical outer flow in a dredged channel.
\end{abstract}

\section{INTRODUCTION}

Ship squat, defined as the reduction of underkeel clearance, is a well-known phenomenon occurring when a ship is moving in shallow or restricted waters. Much research has been devoted to its accurate prediction, leading to a plethora of methods and approaches to the problem. Some of these are empirical methods, which are easy to use, but are reliable only for an early design stage [1]-[5]. Alternatively, researchers have developed analytical methods that make use of the assumptions inherent in potential flow theory, namely, that the flow is inviscid, irrorational and incompressible. Among these, some employ a linear model [6]-[9]. Naturally, experimental investigations [10]-[14] provide the most accurate results, and should be performed if possible. However, the availability of testing facilities, time required to perform the experiment, and the cost are highly prohibitive, hence the need to develop accurate models. To make matters worse, relying solely on experiments, one would need to perform a large number of runs to account for all possibilities. A rapidly emerging alternative is provided by Computational Fluid Dynamics (CFD). Although this approach has its own limitations, such as the computational cost, and knowledge required to perform a simulation, it is rapidly gaining popularity [15].

The present work will focus on a particular case of ship shallow water hydrodynamics using CFD - that of critical flow. This is used to describe that the flow speed matches that of the wave in a particular shallow water region. Commonly, this is expressed by the Depth Froude number [16], $F_{h}$, shown in Eq. (1).

$F_{h}=\frac{U}{\sqrt{g h}}$

Where $U$ is the speed, $h$ is the depth and $g$ is the gravitational acceleration. When the Depth Froude number is smaller than 1, the flow is subcritical, whereas when it is larger than 1 , it is supercritical. The fact that this parameter depends on the water depth gives us the opportunity to investigate what happens around the critical limit $\left(F_{h}=1\right)$ without resorting to unrealistically high speeds, as one would in aerodynamics where $F_{h}$ is replaced by the Mach number. What's more, incorporating two regions, each with different depths, hereafter referred to as dredged channels, gives us even more flexibility to accomplish our task.

NOMENCLATURE
$\begin{array}{ll}F_{h}- & \text { Depth Froude number }[-] \\ U- & \text { Speed }[\mathrm{m} / \mathrm{s}] \\ g- & \text { Gravitational acceleration }\left(9.81\left[\mathrm{~m} / \mathrm{s}^{2}\right]\right) \\ \rho- & \text { Water density }\left(988.8\left[\mathrm{~kg} / \mathrm{m}^{3}\right]\right) \\ h- & \text { Water depth }[\mathrm{m}] \\ L- & \text { Ship length }[\mathrm{m}] \\ w- & \text { Channel width }[\mathrm{m}] \\ \Delta t- & \text { Time step [s] } \\ R e- & \text { Reynolds number }[-] \\ T- & \text { Ship draught }[\mathrm{m}]\end{array}$

\section{A SHORT REVIEW OF CURRENT PRACTICES}

There are several reasons why the critical speed in a dredged channel is a case of particular interest. Perhaps one of the driving factors is that the vast majority of theories (especially those 
based on the slender body theory) break down when $F_{h}=1$ [6], [7]. Some notable attempts at removing the singularity of analytical methods at the critical speed include Gourlay and Tuck [17], where the linear form of the solution was preserved. Others, arrived at a nonlinear solution, Lea and Feldman [18], however, these methods have not been widely used. One might expect that panel methods might be the answer, but the linearised conditions imposed by many of them are bound to run into the same problems the slender body methods do - strong nonlinearity and viscous effects. This is especially true for very shallow water [19], and near the critical speed, where these phenomena dominate the flow characteristics. Having said that, it is worth noting that several recently developed panel methods, such as that of Yuan and Incecik [20], both in waves [21] and in still water, show good agreement with experimental results even in very shallow waters. Alongside these, it is worthwhile to consider the work of Mei and Choi [22], Reza and Mei [23], which tackle the critical speed in uniform shallow water. On the other hand, some recent work has been done in predicting the supercritical - subcritical flow regime in a dredged channel [24]. These include a nonlinear, and dispersive method [24]-[27], however, they have only been applied to simple hulls and fail to address the critical speed.

To further reinforce the applicability of the present investigation, dredging is the only technique available to allow bigger ships to enter inland waterways and shallow ports, whose importance is crucial [28].

While potential flow theories rely on assumptions, CFD can capture all underlying phenomena and predict the non-linear viscous behaviour. For instance, Prakash and Chandra [29] simulated all flow regimes in a uniform bathymetry. In the present study, the speed can be kept low by requiring that the outer region is critical, thus, maintaining realistic speeds for large ships, which was impossible in Prakash and Chandra [29].

In the authors' opinion, another reason is that one of the most popular methods for estimating ship squat in dredged channels is that of Beck et al. [8]. This method predicts that at the critical outer speed, the dredged channel becomes equivalent to a surface piercing canal, with width equal to the interior (dredged) region [30]. The pressure field, caused by the ship in the exterior region extends to infinity without changing, which is unrealistic [31]. It is exactly this prediction that can be exploited to showcase the strengths of CFD compared to other methods.

Considering the unresolved challenges briefly outlined above, it is surprising that it was in the 1890s that Michell [32] developed the foundations of the theory used by Beck et al. [8], which preceded the analogous aerodynamic theory [33].

One final interesting property to be examined is that of wave refraction due to a step change, considered by Lamb [34] and later by Bartholomeusz [35]. This is because, as affirmed by Tunaley [36], in shallow water, the wake pattern is strongly dependent on ship speed and depth, which causes the half-angle of wave propagation to theoretically approach 90 degrees at $F_{h}=$ 1 . Thus, the present paper will examine the influence of critical flows on the sinkage, trim, resistance, and wave pattern.
The remainder of this work will be concerned with the casestudy selection, outlined in the following section. Then, the CFD numerical implementation and physics modelling are briefly presented, before the resulting data is shown accompanied by a brief discussion on its significance.

\section{CASE-STUDY SELECTION}

Throughout this work, heavy reliance will be placed on Tezdogan et al. [37] and Terziev et al. [38] because the CFD setup has been kept identical. The only changes arise from the alterations to the domain arrangement and speeds examined. To compare the results, an in-house code employing the slender body theory of Tuck [6], [7] and Beck et al. [8] is used. Unfortunately, to the authors' knowledge, no experiments have been performed to examine the current topic. Therefore, the abovementioned studies provide the only form of comparison possible at this stage.

The purpose of this study being to investigate critical exterior flows meant that a natural starting point would be to make use of the results of Terziev et al. [38] for a canal. This is because, as explained previously, we expect the results to converge to a single point when $F_{h}=1$ in the case of slender body theory. Furthermore, this reduces the number of simulations required in the present work. Thus, we have restricted our choice of hull forms to the Duisburg Test Case (DTC), which was created for benchmark purposes by el Moctar et al. [14]. Furthermore, to retain consistency, the depth has to be kept the same as that in Terziev et al. [38], because, as explained previously, all investigated parameters are strongly dependent on this metric. Doing so not only determines the hull form and depth, but also the scale factor, which, naturally, must be identical as the aforementioned study (1:40). The hull sections of the DTC are shown in Figure 1 and the vessel's principal characteristics are given in Table 1.

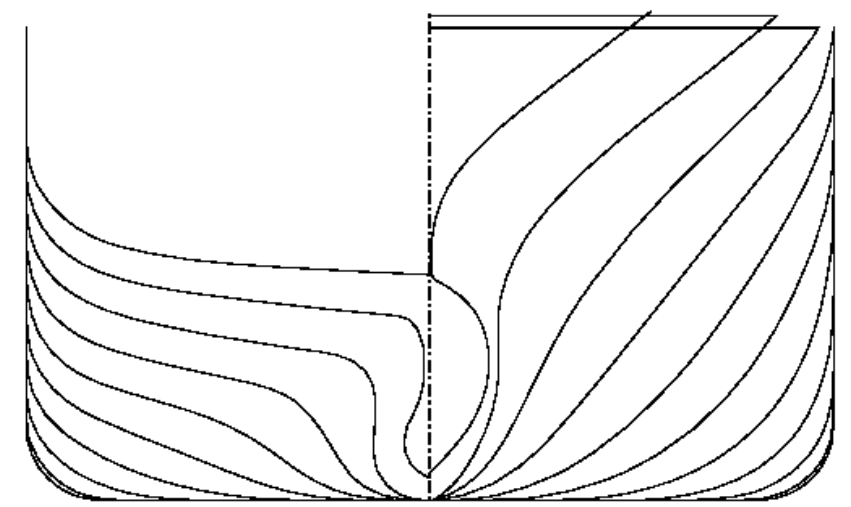

Figure 1. Hull sections of the DTC, taken from el Moctar et al.

[14]

Table 1. DTC principal characteristics (scale factor 1:40)

\begin{tabular}{|l|l|l|l|}
\hline Property & Unit & Full-scale & Model-scale \\
\hline Length $(L)$ & $\mathrm{m}$ & 355 & 8.875 \\
\hline Beam $(B)$ & $\mathrm{m}$ & 51 & 1.275 \\
\hline Draught $(T)$ & $\mathrm{m}$ & 14.5 & 0.363 \\
\hline
\end{tabular}




\begin{tabular}{|l|l|l|l|}
\hline Displacement $(\nabla)$ & $\mathrm{m}^{3}$ & 173814.762 & 2.716 \\
\hline Block coefficient $\left(C_{B}\right)$ & - & 0.661 & 0.661 \\
\hline Wetted area $(S)$ & $\mathrm{m}^{2}$ & 22352 & 13.970 \\
\hline $\begin{array}{l}\text { Longitudinal centre of } \\
\text { buoyancy }(L C B)\end{array}$ & $\mathrm{m}$ & 174.531 & 4.363 \\
\hline $\begin{array}{l}\text { Vertical centre of } \\
\text { gravity-from keel }(V C G)\end{array}$ & $\mathrm{M}$ & 23.28 & 0.852 \\
\hline Metacentric height $\left(M_{T}\right)$ & $\mathrm{m}$ & 1.677 & 0.042 \\
\hline
\end{tabular}

As a starting point, the sinkage, trim, and resistance obtained in Terziev et al. [38] for $F_{0}=0.3,0.4$ are used. Here, the 0 subscript refers to the interior region, while the $\infty$ subscript will refer to the exterior region, as shown in Figure 2. This allows the present work to mainly focus on critical flows in dredged channels at those speeds. Using Eq. (1) and the depth $\left(h_{0}-\right.$ interior depth, and $h_{\infty}$ - exterior depth) for the interior region used in Terziev et al. [38] $\left(h_{0} / T=1.3\right)$ in model scale, we arrive at two $h_{\infty} / h_{0}$ ratios. Namely, $h_{\infty} / h_{0}=0.09$, and $h_{\infty} / h_{0}=0.16$, which guarantee that $F_{\infty}=1$ for the two values of $F_{0}$ mentioned previously $\left(F_{0}=0.3\right.$ for $h_{\infty} / h_{0}=0.09$ and $F_{0}=0.4$ for $\left.h_{\infty} / h_{0}=0.16\right)$. The case-studies are summarised in Table 2, where the canal cases of Terziev et al. [38] have also been added. For completeness, the examination has been extended to include $F_{\infty}=0.99$ and 1.01 for each case. This is to allow the study to gauge the sensitivity of the sinkage, trim, resistance, and wave pattern to the change in flow mode. The exterior depth Froude number has been altered by a slight adjustment to the speed in this case rather than depth. Thus, we have incorporated the following flow regimes: sub-sub, sub-critical, and sub-super. A super-super case is not worthwhile to examine, as it is highly unlikely to occur in practice.

Table 2. Summary of case-studies

\begin{tabular}{|l|c|l|l|l|}
\hline $\begin{array}{l}\text { Case- } \\
\text { study }\end{array}$ & $F_{0}$ & $F_{\infty}$ & $\begin{array}{l}\text { Model-scale } \\
\text { velocity [m/s] }\end{array}$ & $\begin{array}{l}\text { Full-scale } \\
\text { velocity [kn] }\end{array}$ \\
\hline $\mathbf{1}$ & 0.297 & 0.990 & 0.638 & 7.849 \\
\hline $\mathbf{2}$ & 0.300 & 1.000 & 0.645 & 7.928 \\
\hline $\mathbf{3}$ & 0.303 & 1.010 & 0.651 & 8.007 \\
\hline $\mathbf{4}$ & 0.300 & - & 0.645 & 7.928 \\
\hline $\mathbf{5}$ & 0.396 & 0.990 & 0.851 & 10.465 \\
\hline $\mathbf{6}$ & 0.400 & 1.000 & 0.860 & 10.571 \\
\hline $\mathbf{7}$ & 0.404 & 1.010 & 0.868 & 10.676 \\
\hline $\mathbf{8}$ & 0.400 & - & 0.860 & 10.571 \\
\hline
\end{tabular}

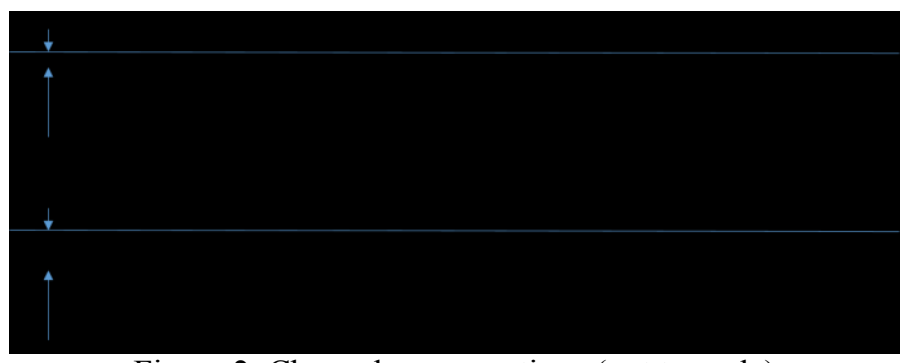

Figure 2. Channel cross-sections (not to scale)

\section{NUMERICAL MODELLING}

One of the remaining questions is that of domain dimensions. The slender body theory assumes infinite extent in all directions, which allows researchers to impose suitable boundary condition at infinity [39]. Of course, this is not possible in CFD, or indeed in reality, which forces the computational domain's width and length to be stated. Being mainly driven by the possibility to maximise results comparison, it is a natural choice to follow the justification of Terziev et al. [38] in this. Namely, the inlet is placed $1.22 \mathrm{~L}$ upstream of the forward perpendicular, and the outlet $2.23 \mathrm{~L}$ downstream of the aft perpendicular. In both cases, the suitable boundary conditions are applied: velocity inlet and pressure outlet, respectively. The domain top, defined as a velocity inlet, is positioned approximately $10 \mathrm{~m}$ from the undisturbed free-surface. The domain bottom has already been illustrated in Figure 2, while the domain sides are placed one ship length from the step and a wall boundary condition is imposed.

To perform the numerical simulations, the commercial CFD software, Star-CCM+ version 13.04, was used, which employs the Finite Volume Method (FVM). The solver divides the computational domain into a finite number of adjoining cells and uses the integral form of the governing equations. The Reynolds Averaged Navier-Stokes (RANS) solver makes use of a predictor-corrector approach to link pressure and momentum.

To model the turbulence in the fluid, a $k-\varepsilon$ model with the all $y^{+}$treatment approach is adopted. With reference to the former, it can be asserted that it has been widely used in both academic and industrial applications [40]-[42]. To further reinforce the case for employing this two equation turbulent kinetic energy - dissipation model, the reader is referred to the wide range of research that has used the $k-\varepsilon$ model: full-scale wake prediction [43], roll decay tests [44], and ship squat predictions [45]. More importantly, it was also employed in Tezdogan et al. [37], for the same ship geometry, whose results were verified against experimental data. It is also worth considering that according to the ITTC [46], two equation models are "by far the most applied ones." Indeed, not only do the findings of Larsson et al. [47] confirm this, they also affirm that "there is no visible improvement of the resistance prediction for turbulence models more advanced than the two-equation models." However, some scattering of the results was found in terms of sinkage and trim predictions. At low underkeel clearance, turbulence modelling increases in importance and can affect the abovementioned values between 3-5\%. Keeping in 
mind the reasoning above, and the fact that Querard et al. [48] found a $25 \%$ reduction in computational time when using the $k-$ $\varepsilon$ model, make this selection seen as a justifiable choice.

Performing a comprehensive turbulence dependence study is not within the scope of the current work, and is suggested as a piece of future research. Provided that an experimental database is available for a range of depths, bathymetries and speeds, a study following the fashion of Pereira et al. [49] must be undertaken.

The all $y^{+}$treatment is a hybrid model that emulates both the low Reynolds number $y^{+}$treatment for $y^{+} \rightarrow 0$, and the high Re $y^{+}$ for $y^{+}>30$. This particular treatment is recommended by Siemens [40] in the context of resistance predictions and is implemented in Tezdogan et al. [37], Terziev et al. [38].

The interface between the two fluid phases (air and water), defined as the free surface, can be modelled via two methods in the present context. Namely, interface capturing and interface tracking. An example of the former is the Level Set method, which uses the displacement of a level curve. The former uses a scalar to describe the boundary between the two phases, which has been selected due to its good volume conservation properties. Making this choice requires that both immiscible fluids account for large parts of the computational domain, while their contact area is relatively small. The VOF method has been successfully used in several studies concerned with shallow water ship performance such as Tezdogan et al. [19], [37], Terziev et al. [38], Tezdogan et al. [50], and therefore applied here. The concept of a flat wave was used to model the fluid movement, where the velocity of water and air were set according to the values shown in Table 2. Additionally, a numerical beach model, the VOF damping length is implemented with a length of $9 \mathrm{~m}$ to prevent reflections.

An investigation of the influence of neglecting the free surface was performed in Razgallah et al. [51] for shallow water manoeuvring. Their findings show that making such an assumption can have a substantial effect on the computed results. What's more, the scattering of predicted values increased as $h_{0} / T$ decreased. A similar argument could apply to insufficient mesh resolution near where the free surface is expected. Naturally, this must encompass its deformations, which are predicted to be considerable due to the nature of the computational domain, that is to say, the presence of a step change in the depth. Volumetric refinements to capture all relevant flow properties were used as in Terziev et al. [38], where the mesh dependence study demonstrated the efficacy of the proposed grid. It is therefore considered that validating this anew is beyond the scope of the current work. However, it is worthwhile to briefly examine the properties of the mesh created using the automatic facilities of Star-CCM+.

To begin with, a region-based (or virtual towing tank-based) mesh is created. Care is taken to ensure that all appendages are accurately encompassed within concentric volumetric refinements. The prism layer mesher is used to fabricate the orthogonal prismatic cells next to the hull. Employing this allows the solver to accurately predict near wall flow properties, as well as flow separation, which in turn can affect integral results such as drag and pressure [40]. The gradients of velocity normal to the wall, are much steeper in the viscous sub-layer than would be predicted if computed otherwise. It is also worth considering that employing the prism layer reduces the discretisation error that smears discontinuities and steep gradients in a FVM advection scheme. Thus, according to Siemens [40] it is not only desirable to use the prism layer mesher, but it also improves the accuracy of the computed result.

The trimmed mesher option was selected to fabricate the high-quality grid. The cells are predominantly hexahedral, which according to Jones and Clarke [52] allows more accurate computations when compared to tetrahedral cells. The resulting mesh is shown in Figure 3, while the number of cells, faces and vertices are summarised in Table 3.

The convection term in the Navier-Stokes equation is discretised using a second order upwind scheme, as this is thought to benefit the turbulence model's accuracy [40]. The segregated flow model was used to solve the governing equations in an uncoupled manner with a SIMPLE algorithm.

To track the motions of the ship, the Dynamic Fluid-Body Interaction module was used, where the ship was allowed to heave and pitch only. Finally, the temporal discretisation is set as first order, where the time step was kept the same as in Terziev et al. [38] and Tezdogan et al. [37], namely, $\Delta t=0.0035 \mathrm{~L} / U$. To ensure good convergence characteristics, the simulations were run for at least 300 seconds in each case.

Table 3. Properties of the mesh generated in Star-CCM+

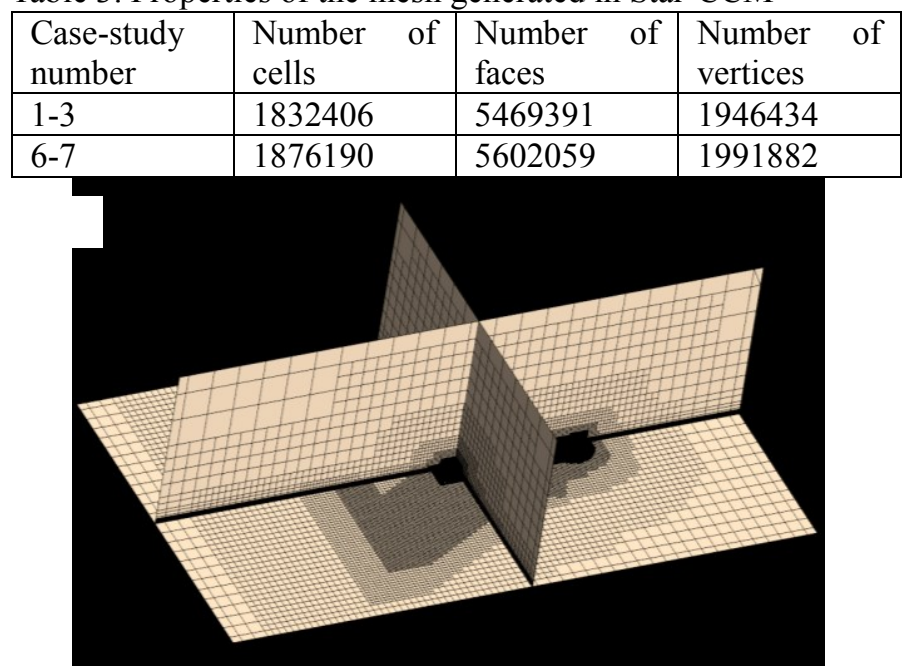

Figure 3. 3-D view of the mesh. Depicted: case-studies 6-7

\section{RESULTS AND DISCUSSION}

The remainder of this paper will deal exclusively with the computed results. To begin with, we examine the wave patterns generated by case-studies 1-3 in Figure 4. Labelled as ' 1 ' is the sub-sub case, where we see that the disturbance caused by the ship creates an easily differentiable water elevation in front of the bow. As $F_{\infty}$ increases, the disturbance begins to look like a polygon, whose sides trace out the edges of the depth discontinuity. Turning our attention to case-study 3 , it seems that 
the polygonal shape of the disturbance has largely shifted back to its previous shape. Perhaps most interesting is the shape of the contours behind the ship in Figure 4. In the sub-sub case, the contours are convex (with respect to the ship centreline), in the critical case - straight, while in the sub-super case, they are concave, in agreement with the wider literature [53]-[56].
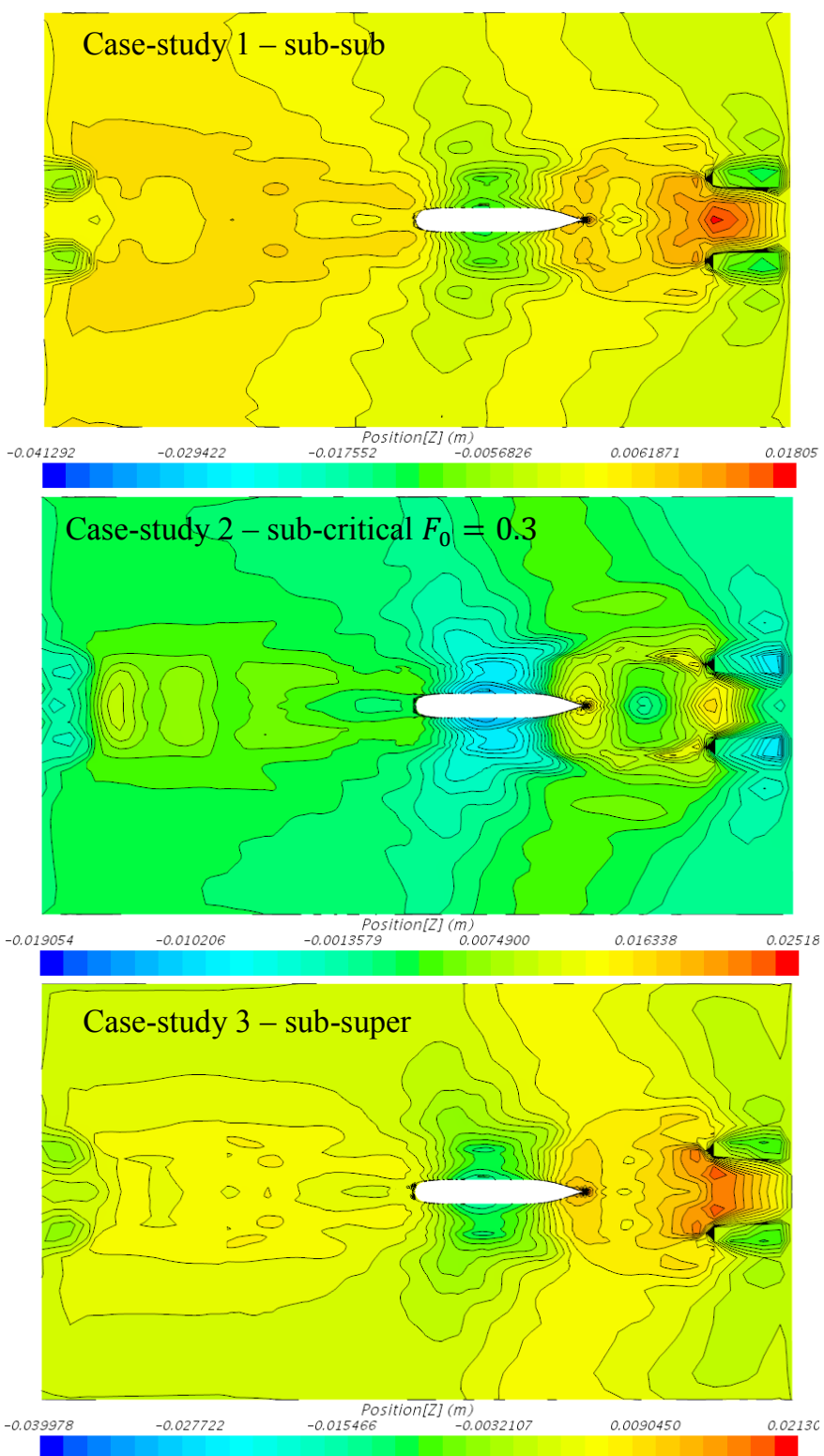

Figure 4. Wave patterns for case-studies 1-3
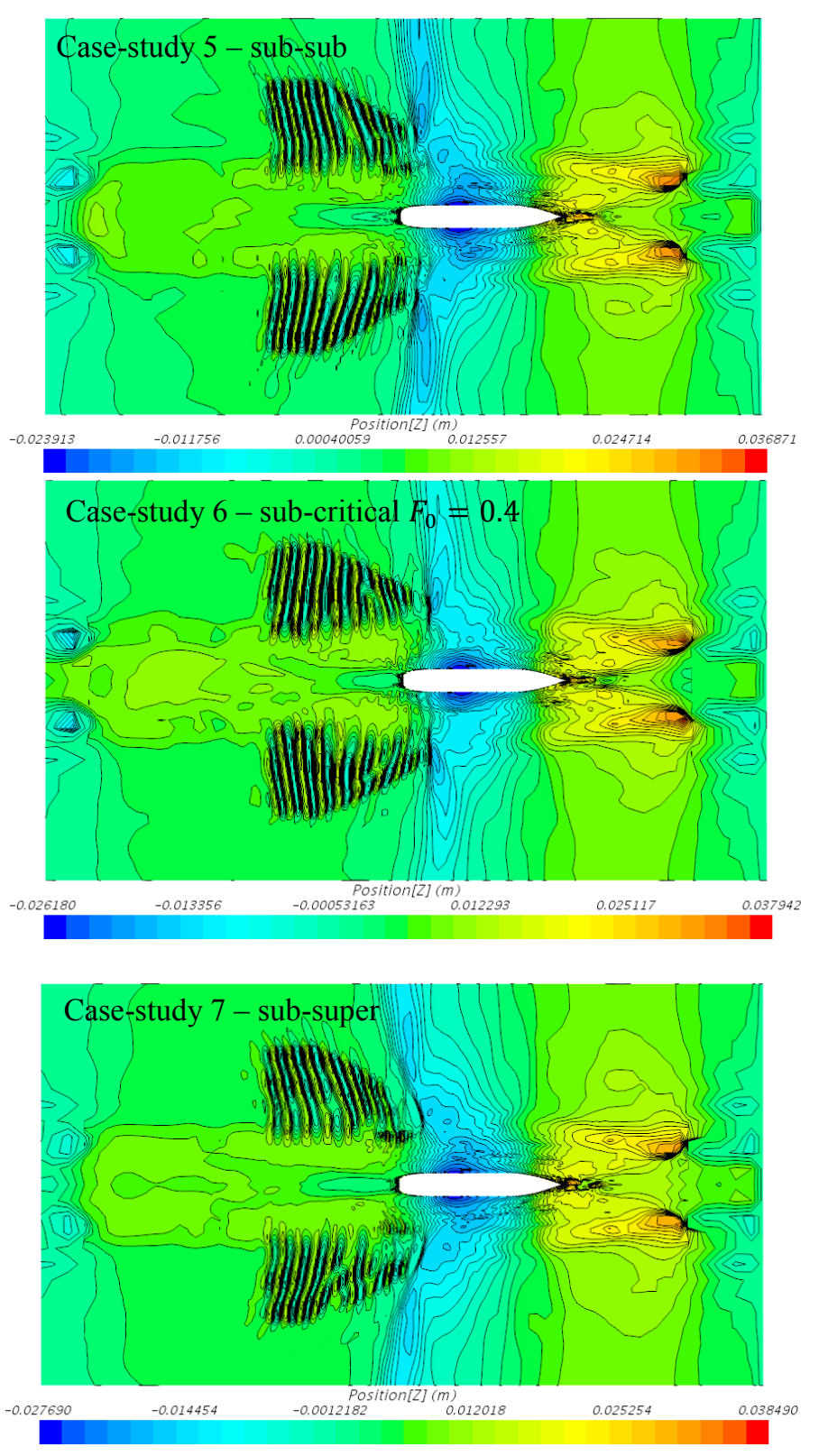

Figure 5. Wave patterns for case-studies 5-7 


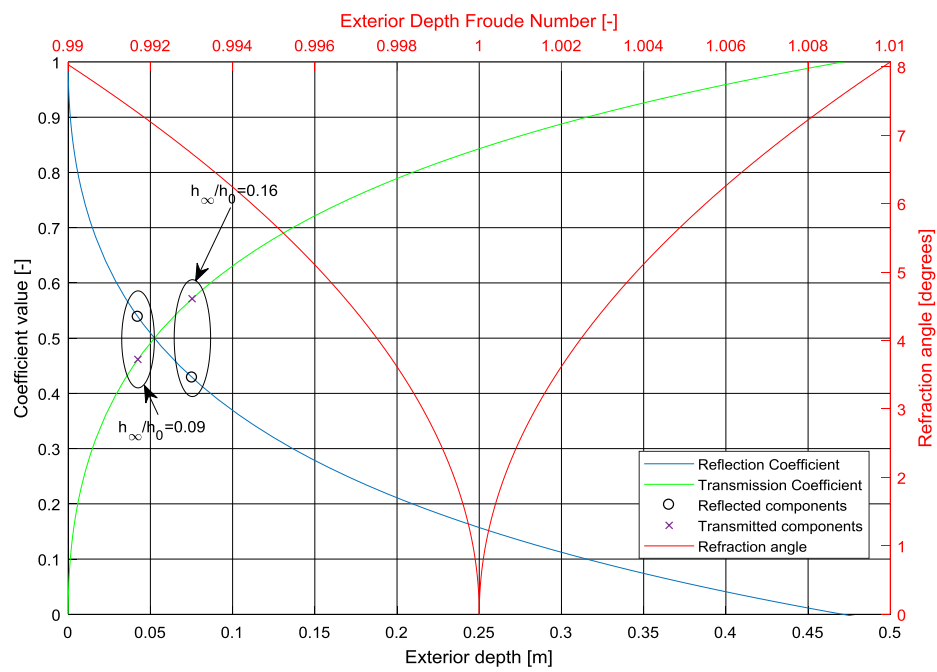

Figure 6. Transmission and reflection coefficients; refraction angle
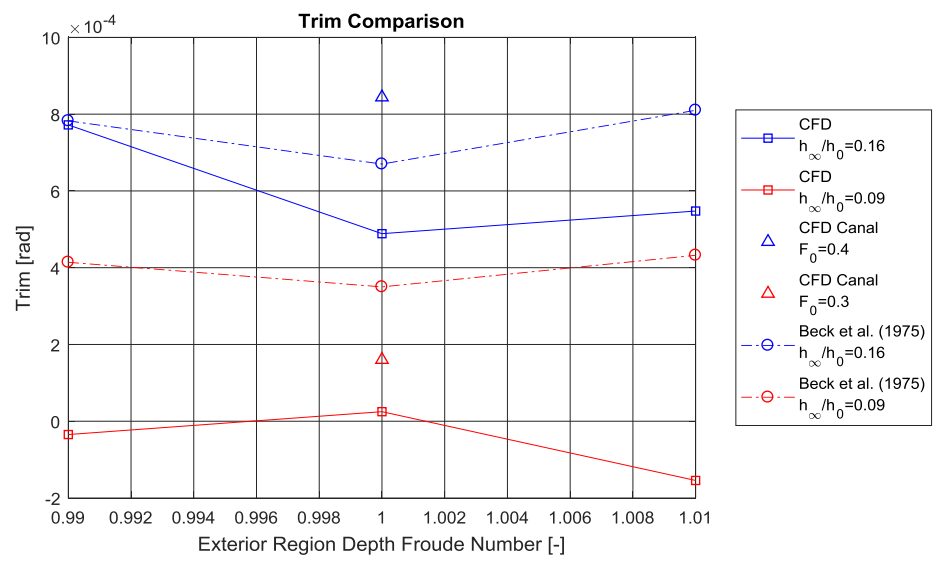

Figure 7. Trim comparison for all case-studies

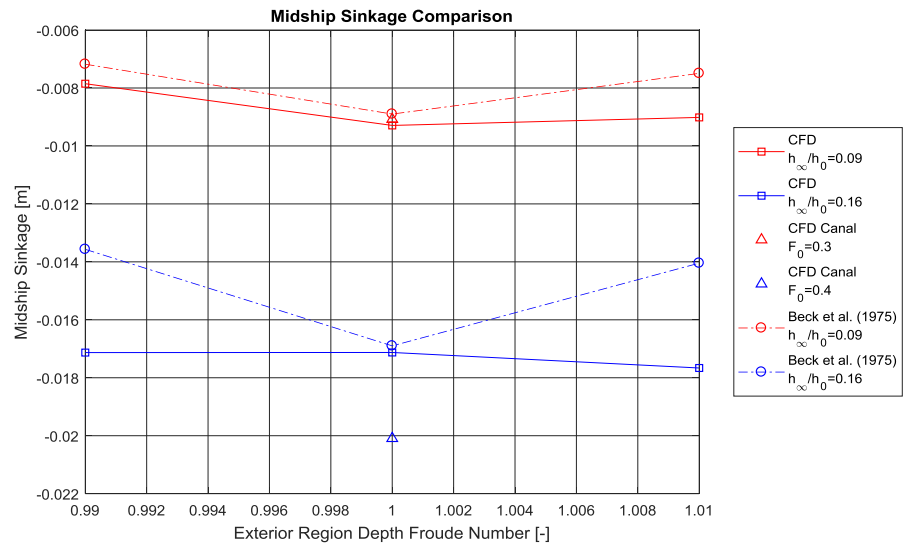

Figure 8. Midship sinkage comparison for all case-studies

In Figure 5, the wave patterns generated by case-studies 5-7 are shown. Here, in contrast to Figure 4, we can see much more clearly the developed wave pattern in both regions.

It is a well-known fact that the wake half-angle in shallow water is different from its deep-water equivalent, albeit virtually indistinguishable in Figure 4. The nondispersive nature of shallow water waves makes the supercritical case the easiest to analyse. In fact, using purely geometrical arguments, one can arrive at an equation that expresses the half-angle in terms of the depth Froude number alone [57].

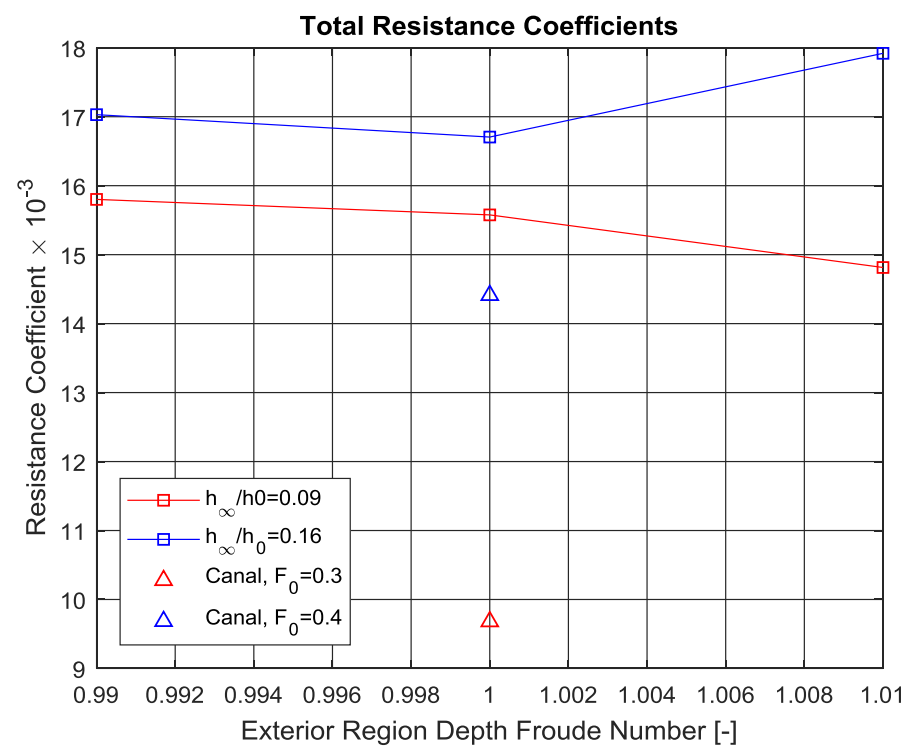

Figure 9. Total resistance coefficients for all case-studies

Unfortunately, subcritical speeds complicate matters substantially, to the extent where such an argument is not only inapplicable, but is an ongoing field of research [58]. This has prompted researchers to develop numerical solutions [59], polynomial approximations [60], as well as explicit solutions [61] (with a slightly reduced accuracy) to the dispersion equation for intermediate depths. Here, we will not make an attempt to replicate nor improve upon these for the simple reason that all published research on the subject agrees that the wake angle begins deviating from the Kelvin wake once the depth Froude number has surpassed a value of 0.5 (see [53]-[56]). This metric, being non-dimensional implies that the argument's validity is retained in the present case.

Having established that our wake half-angle attains a value of $19.47^{\circ}$ in all examined case-studies, we can determine the angle at which the wave refracts at the step. According to Beck et al. [8], water waves obey Snell's law of refraction, but also, an equation is given for the supercritical outer flow case in the abovementioned work. Namely, the refraction angle is $\theta=$ $\cot ^{-1}\left(\sqrt{1-F_{\infty}^{2}}\right)$ for $F_{\infty}<1$, and $\theta=\cot ^{-1}\left(\sqrt{F_{\infty}^{2}-1}\right)$ for $F_{\infty}>1$, which depends solely on the exterior flow. Clearly, when $F_{\infty}=1$, the refracted angle has to be 0 , which is shown in Figure 5: case-study 6. Shown in Figure 6 is the refraction angle, which because of the way the case-studies were set up, is identical between the two groups of case studies. Here, we have also made use of the reflection coefficient defined in Bartholomeusz [35], while the transmission coefficient is simply $1-$ the reflection coefficient. More formally, these express the ratio of the transmitted or reflected wave component to the 
incident wave (also given in Marshall and Naghdi [62]). The points which represent the current case-studies are marked in Figure 6 for clarity. According to Newman [63], the energy transmitted to the shallow region vanishes at a rate proportional to $h_{\infty}$, such that the transmitted wave's height is approximately twice that of the incident wave. This is perhaps part of the reason why we only observe ripples in the exterior region. The predictions made in terms of refraction angle seem to agree well with Figure 5. In the subcritical case, we observe a slight inclination with respect to the normal of the channel/ship centreline, which is also present in the supercritical case. In the critical exterior flow, the ripples generated by the ship do not seem to agree with the 0 degree refraction prediction. In fact, they seem to be, at least in part, tilted towards the inlet. Whether this is due to the highly complex nature of the problem or due to the assumptions in potential flow theory, which was used to derive the relationship, is not known. It is also worth mentioning that Bartholomeusz [35] performed his research because of the simplistic assumption of no vertical acceleration near the step was made in Lamb [34], although the former ([35]) ended up replicating the final result of the latter ([34]). Later these were criticised by Newman [63], where a more rigorous derivation is presented. The applicability of the coefficients is also questionable due to the fact that they were derived for long waves. Nevertheless, it is considered that they can provide a first estimate of the transmitted and reflected components.

In any case, we can make a qualitative distinction of the disturbance generated by the change of flow mode. In terms of quantitative impact, Figure 7 shows that the trim is substantially different between all case-studies, as well as canals taken from Terziev et al. [38]. As expected, the slender body theory results show some deviation, which, keeping in mind the y-scale, is rather small. In all cases, the canal trim is higher than the critical dredged channel. This suggests that although the critical flow has a pronounced influence on ship hydrodynamics, it is not as strong as that caused by a canal. Indeed, recalling the slender body prediction, that the pressure field when $F_{\infty}=1$ is transversely uniform and extends infinitely in the y-direction gives us an idea of the role on nonlinearities. These are expressed in a rapid reduction in the length (along the direction of motion) of the free surface depression near the hull across the step. Then, the disturbance seems to decay rather slowly. To determine the extent required for this to be fully eliminated would imply an additional study, where the domain width would probably exceed its length. Doing so, however, requires unrealistically wide channels, in which case, doubt can be placed over whether such a channel could exist in reality. This is therefore not undertaken here.

In terms of midship sinkage predictions (Figure 8), we confirm the fact that in the low speed range, the slender body theory can provide very good estimates. In the $h_{\infty} / h_{0}=0.09$ case, the predictions are very close. It could be speculated that this is because for lower speeds, nonlinearities play a small role. Seeking to confirm this, we can invoke the remainder of results - for $h_{\infty} / h_{0}=0.16$, where we see a greater disagreement. Finally, the canal result for $F_{0}=0.4$ seems to provide a higher sinkage and trim. The same trend, albeit less pronounced, can be observed in the lower speed case.

With respect to resistance coefficients, shown in Figure 9, we find the surprising fact that both canal results are lower than their dredged counterparts. The more restricted $h_{\infty} / h_{0}=0.09$ shows a slight resistance reduction in the supercritical exterior case. Whether this is due to a spike in the wave resistance at the critical point requires further investigations.

Perhaps the greatest deficiency of the slender body theory is that it cannot provide resistance results. According to Tuck [64], the fact that Michell's [32] formula for wave resistance (in essence) ran into D'Alambert's paradox was the main reason why his achievement was largely overlooked. Indeed, it is striking that in the past decade ([65] and [66]), ongoing research has shown the applicability of Michell's wave resistance formula in deep waters. However, in what seems to be the age of CFD, it is unlikely that much more work will be done on the subject. With more modern tools such as that of Yuan [67], capable of providing accurate results, and the majority of research published now dealing with CFD, it is likely that the abovementioned formula will remain a tool for the initial design stages only.

\section{CONCLUSION}

A study on the effects of mixed flow on ship hydrodynamics was undertaken using CFD and the slender body theory. The hypothesis of potential flow was tested - that a critical exterior flow is equivalent to a surface piercing canal with width equal to the interior section of the dredged channel. To accomplish this, available data for a canal was used. The results focused on were the generated wave patterns, midship sinkage, trim, and resistance coefficients. A set of crude approximations were used to provide a first estimate at the reflection and transmission of ship-generated waves based on the well-known results of Lamb [34] and Bartholomeusz [35]. A quick and simple way to predict the wave refraction angle based on Beck et al. [8] was used, with variable success in terms of accuracy.

The obtained values show a complex relationship between sinkage and trim in all different flow modes examined. The set of obtained results suggests that in a canal, ships have a tendency to sink and trim more than in a dredged channel. Therefore, a greater risk of grounding is expected. Surprisingly however, the canal case was shown to be favourable in terms of resistance. It is speculated that the root cause of this may be that the wave resistance component increases in relative importance near critical flows. Whether this is the sole reason for the observed resistance coefficient values remains to be seen. An attempt to calculate the wave resistance was not undertaken because of the problems one runs into in shallow water resistance prediction techniques. To estimate wave resistance, the current practice is to use a potential flow tool [67], wave cut analysis [68], or direct pressure integration [69]. All of these have their distinct advantages and disadvantages, however, they would substantially complicate the present study since we have two distinct flow fields. Alternatively, empirical corrections based on the form factor approach have been published [16]. Their 
reliability could be questioned in the general case of a uniform shallow water, let alone in the present case.

It is an irrefutable fact that more experimental work is of paramount importance in the field of shallow water hydrodynamics. Recent work, such as that of Mucha et al. [13] and Mucha et al. [70] will undoubtedly aid in this endeavour.

\section{ACKNOWLEDGMENTS}

Results were obtained using the ARCHIE-WeSt High Performance Computer (www.archie-west.ac.uk) based at the University of Strathclyde.

The corresponding author would like to thank Miss Dilyana Nikolova for her help with the final proofreading.

\section{REFERENCES}

[1] C. B. Barrass and D. R. Derrett, "Chapter 42 - Ship Squat in Open Water and in Confined Channels," Sh. Stab. Masters Mates, pp. 367-388, 2012.

[2] A. Millward, "A review of the prediction of squat in shallow water," J. Navig., pp. 77-88, 1996.

[3] J. P. Hooft, "On the critical speed range of ships in restricted waterways," Int. Shipbuild. Prog., vol. 16, no. 177, pp. 145-154, 1969.

[4] N. E. Eryuzlu and R. Hausser, "Experimental investigation into some aspects of large vessel navigation in restricted waterways," in Symp Proc on Asp of Nav of Constraint Waterways, 1978.

[5] E. Rotteveel, R. Hekkenberg, and J. Liu, "Design guidelines and empirical evaluation tools for inland ships," Eur. Inl. Waterw. Navig. Conf., pp. 1-13, 2014.

[6] E. O. Tuck, "Shallow-Water Flows Past Slender Bodies," J. Fluid Mech., vol. 26, no. 1966, pp. 81-95, 1966.

[7] E. O. Tuck, "Sinkage and Trim in Shallow Water of Finite Width," Schiffstechnik, vol. 14, no. 73, pp. 92-94, 1967.

[8] R. F. Beck, J. N. Newman, and E. O. Tuck, "Hydrodynamic forces on ships in dredged channels," $J$. Sh. Res., vol. 19, no. 3, pp. 166-171, 1975.

[9] J. X. Yao and Z. J. Zou, "Calculation of ship squat in restricted waterways by using a 3D panel method," $J$. Hydrodyn., vol. 22, no. 5 SUPPL. 1, pp. 472-477, 2010.

[10] H. Zeraatgar, K. A. Vakilabadi, and R. Yousefnejad, "Parametric Analysis of Ship Squat in Shallow Water by Model Test," Brodogradnja, vol. 62, no. 1, pp. 37-43, 2011.

[11] M. Vantorre, "Ship behaviour and control in muddy areas: State of the art," in Third International Conference on Manoeuvring and Control of Marine Craft (MCMC 94), 1994, pp. 1-10.

[12] E. Lataire, M. Vantorre, and G. Delefortrie, "The Influence of the ship's speed and distance to an Arbitrarily shaped Bank on Bank Effects," Proc. ASME 2015 34th Int. Conf. Ocean. Offshore Arct. Eng., vol. 140, no. April, pp. 1-9, 2015.
[13] P. Mucha, O. el Moctar, T. Dettmann, and M. Tenzer, "Inland waterway ship test case for resistance and propulsion prediction in shallow water," Sh. Technol. Res., vol. 64, no. 2, pp. 106-113, 2017.

[14] O. el Moctar, V. Shigunov, and T. Zorn, "Duisburg Test Case : Post-Panamax Container Ship for Benchmarking," Sh. Technol. Res. J., vol. 59, no. 3, pp. 50-64, 2012.

[15] F. Stern, J. Yang, Z. Wang, H. Sadat-Hosseini, and M. Mousaviraad, "Computational ship hydrodynamics: Nowadays and way forward," Int. Shipbuild. Prog., vol. 60, no. 1-4, pp. 3-105, 2013.

[16] A. F. Molland, S. R. Turnock, and D. A. Hudson, "Restricted Water Depth and Breadth," in Ship Resistance and Propulsion: Practical Estimation of Ship Propulsive Power, 2nd ed., Cambridge : Cambridge University Press, 2017, pp. 102-112.

[17] T. Gourlay and E. O. Tuck, "The maximum sinkage of a ship,” J. Sh. Res., vol. 45, no. 1, pp. 50-58, 2001.

[18] G. K. Lea and J. P. Feldman, "Transcritical flow past slender ships," in 9th Symposium on Naval Hydrodynamics, 1972, pp. 1527-1542.

[19] T. Tezdogan, A. Incecik, and O. Turan, "Full-scale unsteady RANS simulations of vertical ship motions in shallow water," Ocean Eng., vol. 123, pp. 131-145, 2016.

[20] Z. Yuan and A. Incecik, "Investigation of side wall and ship model interaction," in 2016 International Conference on Maritime Technology, 2016, pp. 1-10.

[21] Z. M. Yuan, A. Incecik, and L. Jia, "A new radiation condition for ships travelling with very low forward speed," Ocean Eng., vol. 88, pp. 298-309, 2014.

[22] C. C. Mei and H. S. Choi, "Forces on a slender ship advancing near the critical speed in a wide canal," $J$. Fluid Mech., vol. 179, no. 1954, pp. 59-76, 1987.

[23] M.-R. Alam and C. C. Mei, "Ships advancing near the critical speed in a shallow channel with a randomly uneven bed," J. Fluid Mech., vol. 616, pp. 397-417, 2008.

[24] Z. hong Zhang, H. Deng, Y. chen Li, and J. nong Gu, "Analytical models of sub-supercritical ship hydrodynamic pressure field with the dispersive effect," Ocean Eng., vol. 133, no. August 2016, pp. 66-72, 2017.

[25] H. Deng, Z. H. Zhang, J. Bin Liu, and J. N. Gu, "Nonlinear effects on hydrodynamic pressure field caused by ship moving at supercritical speed in shallow water," Ocean Eng., vol. 82, pp. 144-149, 2014.

[26] H. Deng, Z. hong Zhang, J. bin Liu, and C. Wang, "Research on hydrodynamic pressure field causing by ship moving in mixed flow," Ocean Eng., vol. 136, no. December 2016, pp. 314-321, 2017.

[27] Z. H. Zhang, H. Deng, and C. Wang, "Analytical models of hydrodynamic pressure field causing by a moving ship in restricted waterways," Ocean Eng., vol. 108, pp. 563-570, 2015.

[28] S. Mihic, M. Golusin, and M. Mihajlovic, "Policy and 
promotion of sustainable inland waterway transport in Europe - Danube River," Renew. Sustain. Energy Rev., vol. 15, no. 4, pp. 1801-1809, 2011.

[29] S. M. N. Prakash and B. Chandra, "Numerical Estimation of Shallow Water Resistance of a River-Sea Ship using CFD," Int. J. Comput. Appl., vol. 71, no. 5, pp. 33-40, 2013.

[30] T. Gourlay, "Slender-body methods for predicting ship squat," Ocean Eng., vol. 35, no. 2, pp. 191-200, 2008.

[31] T. Gourlay, "ShallowFlow: A Program to Model Ship Hydrodynamics in Shallow Water," in OMAE 2014, 2014, p. 8.

[32] J. H. Michell, "The wave-resistance of a ship," London, Edinburgh, Dublin Philos. Mag. J. Sci., vol. 45, no. 272, pp. 106-123, 1898.

[33] E. O. Tuck, "Hydrodynamic Problems of Ships in Restricted Waters," Annu. Rev. Fluid Mech., vol. 10, pp. 33-46, 1978.

[34] H. Lamb, "Hydrodynamics," Cambridge Univ. Press, vol. 6th revise, pp. 262-264, 1932.

[35] B. Y. E. F. Bartholomeusz, "Reflexion of long waves at a step," Math. Proc. Cambridge Philos. Soc., vol. 54, no. 1, pp. 106-118, 1958.

[36] J. K. E. Tunaley, "Ship Wakes in Shallow Waters," LRDC Rep., pp. 6-9, 2014.

[37] T. Tezdogan, A. Incecik, and O. Turan, "A numerical investigation of the squat and resistance of ships advancing through a canal using CFD," J. Mar. Sci. Technol., vol. 21, no. 1, pp. 86-101, 2016.

[38] M. Terziev, T. Tezdogan, E. Oguz, T. Gourlay, Y. K. Demirel, and A. Incecik, "Numerical investigation of the behaviour and performance of ships advancing through restricted shallow waters," J. Fluids Struct., vol. 76, pp. 185-215, 2018.

[39] J. Newman, "Applications of slender-body theory in ship hydrodynamics," Annu. Rev. Fluid Mech., no. 15, pp. 67-94, 1970.

[40] Siemens, "Star-CCM+ User Guide version 13.04." 2018.

[41] F. Cakici, O. F. Sukas, O. K. Kinaci, and A. D. Alkan, "Prediction of the vertical motions of the dtmb 5415 ship using different numerical approaches," Brodogradnja, vol. 68, no. 2, pp. 29-44, 2017.

[42] Y. H. Ozdemir, T. Cosgun, A. Dogrul, and B. Barlas, "A numerical application to predict the resistance and wave pattern of KRISO containership," Brodogradnja, vol. 67, no. 2, pp. 47-65, 2016.

[43] S. Park, G. Oh, S. Hyung Rhee, B. Y. Koo, and H. Lee, "Full scale wake prediction of an energy saving device by using computational fluid dynamics," Ocean Eng., vol. 101, pp. 254-263, 2015.

[44] S. Mancini, E. Begovic, A. H. Day, and A. Incecik, "Verification and validation of numerical modelling of DTMB 5415 roll decay," Ocean Eng., vol. 162, no. June 2017, pp. 209-223, 2018.

[45] J. Jachowski, "Assessment of ship squat in shallow water using CFD," Arch. Civ. Mech. Eng., vol. 8, no. 1, pp. 27
36,2008

[46] ITTC, "ITTC - Recommended Procedures and Guidelines - Practical guidelines for ship CFD applications. 7.5-03-02-03 (Revision 01)," ITTC Recomm. Proced. Guidel., p. 19, 2014.

[47] L. Larsson, F. Stern, and M. Visonneau, Numerical Ship Hydrodynamics: An assessment of the Gothenburg 2010 Workshop. Springer, 2014.

[48] A. Quérard, P. Temarel, and S. R. Turnock, "Influence of viscous effects on the hydrodynamics of ships-like sections undergoing symmetric and anti-symmetric motions, using RANS," in Proceedings of the ASME 27th International Confer ence on Offshore Mechanics and Arctic Engineering OMAE2008, 2008, pp. 1-10.

[49] F. S. Pereira, L. Eça, and G. Vaz, "Verification and Validation exercises for the flow around the KVLCC2 tanker at model and full-scale Reynolds numbers," Ocean Eng., vol. 129, no. November 2016, pp. 133-148, 2017.

[50] T. Tezdogan, A. Incecik, O. Turan, and P. Kellett, "Assessing the Impact of a Slow Steaming Approach on Reducing the Fuel Consumption of a Containership Advancing in Head Seas," Transp. Res. Procedia, vol. 14, no. December, pp. 1659-1668, 2016.

[51] I. Razgallah, S. Kaidi, H. Smaoui, and P. Sergent, "The impact of free surface modelling on hydrodynamic forces for ship navigating in inland waterways: water depth, drift angle, and ship speed effect," J. Mar. Sci. Technol., pp. 1-22, 2018.

[52] D. A. Jones and D. B. Clarke, "Fluent Code Simulation of Flow around a Naval Hull: the DTMB 5415," Def. Sci. Technol. Organ. Victoria (Australia), Marit. platforms Div., 2010

[53] T. Inui, "On Deformation, Wave Patterns and Resoncance Phenomenon of Water Surface due to a Moving Disturbance. II," Proc. Physico-Mathematical Soc. Japan, vol. 18, no. 2, 1936.

[54] T. Inui, "On Deformation, Wave Patterns and Resoncance Phenomenon of Water Surface due to a Moving Disturbance. I," Proc. Physico-Mathematical Soc. Japan, vol. 18, no. 2, 1936.

[55] T. Havelock, "The Propagation of Groups of Waves in Dispersive Media, with Aplication to Waves on Water produced by a Travelling Disturbance," pp. 422-451, 1924.

[56] R. Yang, I. V Shugan, and M. Fang, "Kelvin ship wake in the wind and waves fiend and on the finite sea depth," Environment, vol. 27, no. 1, pp. 71-77, 2011.

[57] S. Rozman, "Wake pattern of a boat," (Doctoral Diss. Ljubljana, Slov. Univ. Ljubliana), 2009.

[58] R. Pethiyagoda, T. J. Moroney, G. J. Macfarlane, J. R. Binns, and S. W. McCue, "Time-frequency analysis of ship wave patterns in shallow water: modelling and experiments," Ocean Eng., vol. 158, no. April, pp. 123131, 2018.

[59] J. N. Newman, "Numerical solutions of the water-wave 
dispersion relation," Appl. Ocean Res., vol. 12, no. 1, pp. 14-18, 1990.

[60] J. N. Hunt, "Direct solution of wave dispersion equation," J. Waterw. Port, Coastal, Ocean Eng., vol. 106, no. 4, pp. 457-459, 1979.

[61] J. Guo, "Simple and explicit solution of wave dispersion equation," Coast. Eng., vol. 45, no. 2, pp. 71-74, 2002.

[62] J. S. Marshall and P. M. Naghdi, "Wave reflection and transmission by steps and rectangular obstacles in channels of finite depth," Theor. Comput. Fluid Dyn., vol. 1, no. 5, pp. 287-301, 1990.

[63] J. N. Newman, "Propagation of water waves over an infinite step," J. Fluid Mech., vol. 23, no. 2, pp. 399415, 1965.

[64] E. O. Tuck, "The wave resistance formula of J.H. Michell (1898) and Its significance to recent research in ship hydrodynamics," J. Aust. Math. Soc. Ser. B. Appl. Math., vol. 30, p. 365, 1989.

[65] E. O. Tuck and L. V Lazauskas, "Drag on a ship and Michell's integral," in 22nd Int. Congress of Theoretical and Applied Mechanics, Adelaide, South Australia, August, 2008.

[66] F. Noblesse, F. Huang, and C. Yang, "The Neumann Michell theory of ship waves," no. October 2011, pp. 51-52, 2013.

[67] Z. Yuan, "Ship Hydrodynamics in Confined Waterways," J. Sh. Res., no. 1, pp. 1-14, 2018.

[68] C.-E. Janson and D. Spinney, "A Comparison of Four Wave Cut Analysis Methods for Wave Resistance Prediction," Sh. Technol. Res., vol. 51, no. 4, pp. 173184, 2004.

[69] M. Yu and J. Falzarano, "Wave resistance determination by pressure integration and wave cut analysis using nonlinear rankine panel method," Ships Offshore Struct., pp. $1-9,2018$.

[70] P. Mucha, O. el Moctar, T. Dettmann, and M. Tenzer, "An experimental study on the effect of confined water on resistance and propulsion of an inland waterway ship," Ocean Eng., vol. 167, no. June, pp. 11-22, 2018. 